\title{
Persistent ductus arteriosus in a 72-year-old woman with paroxysmal atrial fibrillation and depression syndrome: a therapeutic and diagnostic problem
}

Adam Rafał Poliwczak¹, Marzena Koziróg¹, Justyna Zabielska1, Agnieszka Bała², Piotr Lipiec², Marlena Broncel ${ }^{1}$

\author{
1Department of Internal Diseases and Clinical Pharmacology, Medical University \\ of Lodz, Poland \\ 2Department of Cardiology, Medical University of Lodz, Poland
}

Submitted: 6 August 2010

Accepted: 3 October 2010

Arch Med Sci 2011; 7, 5: 914-917

DOI: 10.5114 /aoms.2011.25572

Copyright (c) 2011 Termedia \& Banach

\begin{abstract}
Treating the elderly is often problematic, especially when congenital heart disease is diagnosed. The aim of this study is to present the case of a 72-year old woman with depression syndrome, paroxysmal atrial fibrillation and past cerebral stroke, in whom persistent ductus arteriosus Botalli was diagnosed. Due to exacerbation of the depressive syndrome, she did not give her consent to further diagnostics, possible interventional procedures and treatment with oral anticoagulants. After intermission of the therapy she was treated with dabigatran. The patient is still undergoing outpatient treatment and so far, no cerebrovascular episodes have been recorded.
\end{abstract}

Key words: atrial fibrillation, persistent ductus arteriosus Botalli, patent foramen ovale, elderly people, dabigatran.

\section{Introduction}

Persistent ductus arteriosus Botalli (PDA) in patients over 65 years old is a rare finding. According to the medical literature, two of the oldest patients in whom PDA has been diagnosed are a 92-year-old Japanese woman [1] and a 90-year-old man from the USA [2].

The frequency of PDA, which is a quite frequent (15-20\%) congenital heart failure in children, has increased in the last two decades. It is caused by a higher survival rate of premature babies [3]. It is reported that rubella virus infection in the first pregnancy trimester accounts for the occurrence of PDA [4].

During the intrauterine life, the ductus arteriosus connects the descending aorta with the left pulmonary artery. After birth, the flow reverses and functional occlusion of the ductus arteriosus occurs. In the majority of infants, the ductus is obliterated during the first month. The PDA leads to a left-to-right shunt of varying intensity.

The main symptoms of PDA are dyspnoea, diminished effort tolerance, and Gibson's machine murmur. Small shunts usually give no symptoms for a long time and they are diagnosed accidentally. Large shunts lead to pulmonary hypertension and the development of Eisenmenger syndrome. The main PDA diagnostic examination is echocardiography, but also

\author{
Corresponding author: \\ Adam Rafał Poliwczak MD, PhD \\ Department of Internal Diseases \\ and Clinical Pharmacology \\ Medical University of Lodz \\ 1/5 Kniaziewicza \\ 91-347 Lodz, Poland \\ Phone: +48 426511059 \\ Fax: +48 426511059 \\ E-mail: \\ adam.poliwczak@umed.lodz.pl
}


computed tomography (CT) and magnetic resonance imaging (MRI) [5]. The final PDA evaluation is made during angiography [4].

The PDA is treated via a thoraco- or sternotomy occlusion. Percutaneous interventional occlusion by unfastened coil or Amplatzer occluder are currently more and more frequent reference techniques $[6,7]$. About $20 \%$ of non-treated PDA patients die before reaching the age of 30 [8].

\section{Case report}

We would like to present the case of a 72-yearold woman suffering from PDA, with patent foramen ovale (PFO), past cerebral stroke and depression syndrome.

The 72-year-old woman was sent to the cardiology outpatient clinic because of recurring episodes of paroxysmal atrial fibrillation (AF), and symptoms of heart failure (NYHA II, periodically NYHA III). As the anamnesis and medical history of the patient revealed, in the past year, 3 or 4 episodes of paroxysmal AF occurred, and for that reason she was twice admitted to hospital and treated in the internal medicine ward. In that time she had cerebral stroke with left-side hemiparesis, moderate aphasia and intermittent bulbar syndrome (the presence of a cerebral ischaemic focal lesion was confirmed by CT examination). In echocardiography recently performed on an outpatient clinic basis, haemodynamically significant PDA was demonstrated. The patient was also treated for hypertension, chronic obstructive pulmonary disease (COPD) and mixed depressive-anxiety disorders. She also underwent strumectomy due to neutral nodular goitre. It was likely that the patient had haemodynamically significant PDA so she was sent to the Department of Internal Diseases with Clinical Pharmacology for further evaluation of the heart defect and possible qualification for percutaneous PDA occlusion. On admission to the hospital the physical examination revealed the presence of bilateral crepitant rales at the base of the lungs and prolonged exhale phase. Heart action was regular (64/min). Her arterial blood pressure was $140 / 80 \mathrm{mmHg}$, BMI $22.5 \mathrm{~kg} / \mathrm{m}^{2}$. On the left margin of the sternum there was quiet systolic murmur (loudness $1 / 6$ by Levin) with no Gibson's machine murmur typical for PDA. Before admission to the department, the patient was treated with clopidogrel, simvastatin, perindopril, metoprolol, levothyroxine, fluticasone/salmeterol, diazepam, estazolam and levomepromazine. Serum plasma investigation and urinalysis did not reveal any abnormalities. ECG: levogram. Sinus regular rhythm $64 / \mathrm{min}$, small progression of $r$ wave in precordial leads V1-V4, inverted T wave in V1-V2, QTc 420 ms. Transthoracic echocardiography revealed the following findings: LVEDD $52 \mathrm{~mm}$, LVESD $34 \mathrm{~mm}$, LA $45 \mathrm{~mm}$, RA $32 \mathrm{~mm}$, PA $35 \mathrm{~mm}$, RVEDD $28 \mathrm{~mm}$, Ao ASC $28 \mathrm{~mm}$, IVSd $10 \mathrm{~mm}$, IVSs $13 \mathrm{~mm}$, PWd $10 \mathrm{~mm}$, PWs $13 \mathrm{~mm}$, SPAP $32 \mathrm{mmHg}$; besides trace of mitral and tricuspid insufficiency, no other flow perturbations or organic changes of the valvular leaflets were found; left ventricle (LV) impaired relaxation, LV symmetric contractility, ejection fraction $E F=62 \%$, TAPSE $24 \mathrm{~mm}$. A left to right shunt between the descending aorta and left pulmonary artery, on the basis of PDA with the diameter circa $8 \mathrm{~mm}$, was found (Figures 1 and 2). On Doppler examination the systolic-diastolic flow was present, Vmax $2.5 \mathrm{~m} / \mathrm{s}$. No pulmonary hypertension occurred. The pulmonary trunk was significantly dilated. A slightly protruded atrial septum with small PFO (3 $\mathrm{mm})$ and small left to right shunt was found (Figure 3).

According to current ESC and ACC/AHA recommendations [7, 9] PDA is regarded as significant when the following are found: LV and/or LA dilatation, LV volume overload, pulmonary hypertension and associated lesions which may occur in PDA. Although the PDA had excessive diameter (ca. $8 \mathrm{~mm}$ ), there was no evidence of clinical or haemodynamic significance. The LV dilatation,
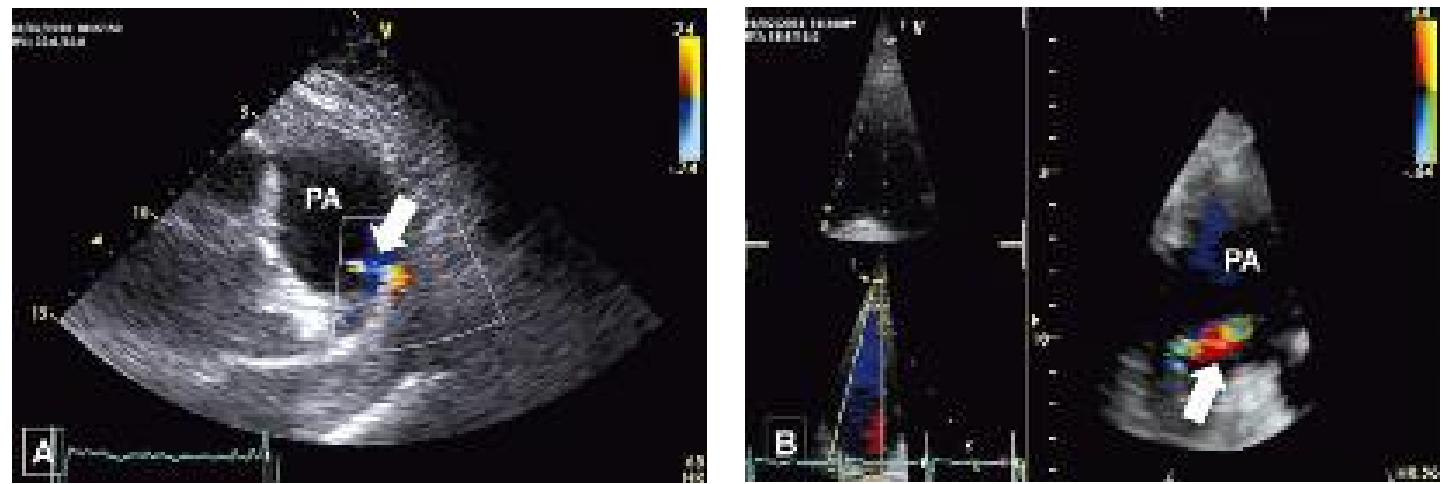

Figure 1. Transthoracic two-dimensional echocardiography (panel A) and three-dimensional echocardiography (panel B). Modified parasternal view with colour Doppler flow mapping reveals presence of turbulent flow (arrow) in dilated pulmonary artery (PA) indicative of left-to-right shunt through patent ductus arteriosus 


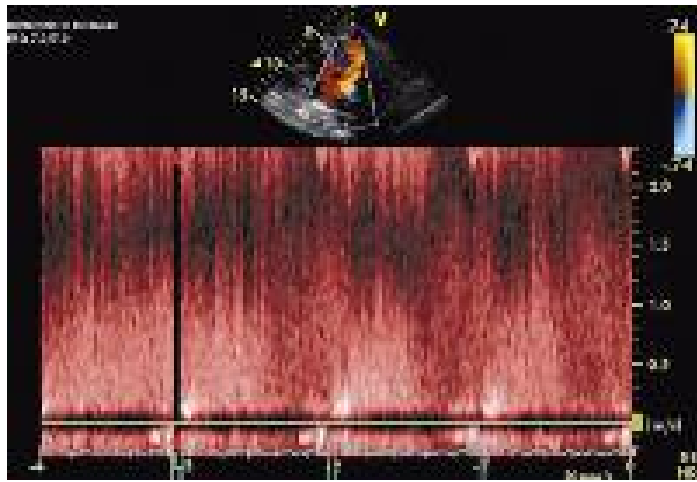

Figure 2. Transthoracic echocardiography with pulsed wave Doppler technique confirms presence of continuous left-to-right shunt through patent ductus arteriosus

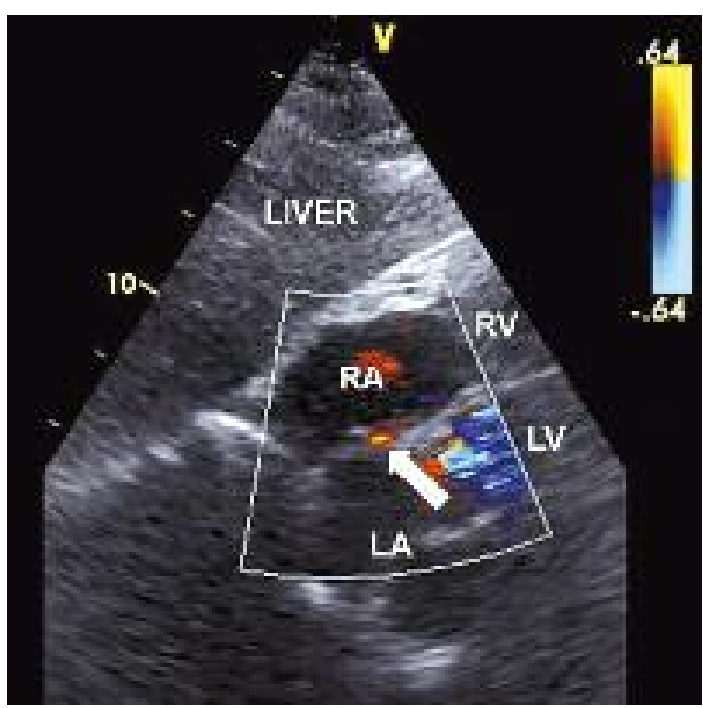

Figure 3. Transthoracic two-dimensional echocardiography. Subcostal view with colour Doppler flow mapping indicates presence of small left-to-right shunt (arrow) through patent foramen ovale $L A$ - left atrium, $R A$ - right atrium, $L V$ - left ventricle, $R V$ - right ventricle

LV volume overload and pulmonary hypertension were not observed. Qp : Qs index was 1.3. No other lesions associated with PDA were observed. Only LA diameter was enlarged ( $45 \mathrm{~mm})$. The small PFO seemed to be of no haemodynamic significance either. Presumably, due to the exacerbation of depressive syndrome, the patient did not give her consent to further diagnostic procedures and possible interventional occlusion. For that reason no further examinations were performed. The lack of haemodynamic significance of PDA and PFO justified the chosen course of treatment. The patient was treated with vitamin $\mathrm{K}$ antagonist (VKA) (recommended INR value was achieved) and infectious endocarditis prophylaxis was applied. The general condition of the patient improved, and no episodes of paroxysmal atrial fibrillation occurred. Discharge recommendations included VKA (acenocoumarol). After 3 weeks of treatment, the patient refused to continue VKA therapy and with no medical consultation she switched to clopidogrel instead. The reason she provided was that she could not accept regular INR blood tests. During an appointment in the outpatient clinic, she was suggested dabigatran therapy $110 \mathrm{mg}$ twice a day, which she accepted. The patient has been monitored cardiologically for 6 months now. Moreover, she has been under the supervision of a psychiatric outpatient clinic too. In that period no heart failure exacerbation, atrial fibrillation or cerebral ischaemic episodes occurred.

\section{Discussion}

According to the current recommendations, a haemodynamically significant PDA, with typical Gibson's machine murmur, should be occluded $[7,9]$. Percutaneous procedures are preferred, but the type of the procedure depends on the PDA diameter and the experience of the scientific staff [5]. Coexistence of other heart or great vessel pathologies may also affect the occlusion method selection. In a case of small PDA of no haemodynamic significance, which can be found only by medical imaging examination, therapeutic management is not so obvious. In these situations many factors, such as the patient's preferences, concomitant diseases, and possible complications of a procedure, should be considered. Life expectancy seems to be an important aspect too. In any case, an individual approach is recommended. There is an additional problem referring to elderly people, who often do not understand the necessity of therapy. In the presented case, besides the somatic diseases, the patient suffered from a depressive syndrome. There was a risk that the exacerbation of this syndrome could lead to non-compliance, and indeed, this was the case. After echocardiographic examination, the patient did not give her consent to further diagnostic and therapeutic procedures. Because of the cerebral stroke history and recurring episodes of paroxysmal atrial fibrillation, we used the $\mathrm{CHADS}_{2}$ scale to estimate the thromboembolic risk. The $\mathrm{CHADS}_{2}$ score was 4 points, which indicated high thromboembolic risk. The VKA was administered and the appropriate INR level was achieved [10]. Unfortunately, the patient's noncompliance and her wilful discontinuance of anticoagulant therapy created a high risk of further thromboembolic episodes. According to the recently published RE-LY trial, we decided to administer dabigatran (Pradaxa ${ }^{\circledR}$ ) [11]. The exacerbation of the depressive syndrome was partly handled by higher doses of antidepressants, although this increased the risk of drug interactions.

In conclusion, therapy of the elderly is often problematic $[12,13]$. This refers to both management 
of common pathologies and congenital heart defects found in the elderly. The appropriate medical treatment is not always accepted by the patient, who does not give his consent or does not understand the aim of therapy. In the reported case, the patient did not consent to PDA occlusion and VKA treatment, and therefore conservative therapy, including dabigatran, a new anticoagulation drug, was applied. The effects of this 6-month-long therapy have been satisfactory so far.

\section{References}

1. Satoh T, Nishida N. Patent ductus arteriosus with infective endocarditis at age 92. Intern Med 2008; 47: 263-8.

2. Wite PD, Mazurkie SJ, Boschetti AE. Patency of the ductus arteriosus at 90. N Eng J Med 1969; 280: 146-7.

3. Mullins CE. Patent ductus arteriosus. In: The science and practice of pediatric cardiology. Garson A, Bricker JT, McNamara DG (ed.). Lea \& Febiger, Philadelphia 1990.

4. Moss and Adams's hart disease in infants, children and adolescents. Lippincot Williams \& Wilkins, Philapelphia 2001.

5. Schneider DJ, Moore JW. Patent ductus arteriosus. Circulation 2006; 114: 1873-82.

6. Kępa C, Demkow M, Rużyłło W, Dzielińska Z, Konka M. Transcatether closure of patent ductus arteriosus a 10-year single centre experience. Eur Heart J 2003; 24 (Suppl): 102

7. Deanfield J, Thaulow E, Warenes C, et al. Management of grown up congenital heart disease. Eur Heart J 2003; 24: 1035-84.

8. Campbell M. Natural history of persistent ductus arteriosus. Br Heart J 1968; 30: 4-13.

9. Warnes CA, Williams RG, Bashore TM, et al. ACC/AHA 2008 Guidelines for the management of adults with congenital heart disease: a report of the American College of Cardiology/American Heart Association Task Force on Practice Guidelines (Writing Committee to Develop Guidelines on the Management of Adults With Congenital Heart Disease): Developed in Collaboration With the American Society of Echocardiography, Heart Rhythm Society, International Society for Adult Congenital Heart Disease, Society for Cardiovascular Angiography and Interventions, and Society of Thoracic Surgeons. Circulation 2008; 118: e714-833.

10. Fuster V, Rydén LE, Cannon DS, et al. ACC/AHA/ESC 2006 guidelines for the management of patients with atrial fibrillation-executive summary: a report of the American College of Cardiology/American Heart Association Task Force and the European Society of Cardiology Committee for Practice Guidelines (Writing Committee to Revise the 2001 Guidelines for the Management of Patients With Atrial Fibrillation). Eur Heart J 2006; 27: 1979-2030.

11. Connolly SJ, Ezekowitz MD, Yusuf S, et al. Dabigatran versus Warfarin in Patients with Atrial Fibrillation. N Engl J Med 2008; 361: 1139-51.

12. Marcum ZA, Handler SM, Boyce R, Gellad W, Hanlon JT. Medication misadventures in the elderly: a lear in review. Am J Geriatr Pharmacother 2010; 8: 77-85.

13. Tomasov P, Linhartova K, Antonova P, Adlova R, Alan D, Veselka J. Combined percutaneous treatment of atrial septal defect and pulmonic or aortic stenosis in adult patients. Arch Med Sci 2010; 6: 976-80. 